\title{
Experiments and Simulations of Penetration into Granite by an Aluminum Shaped Charge
}

M. J. Murphy, G. Randers-Pehrson, RM. Kuklo, T. A. Rambur, L. L. Switzer, M. A. Summes

This article was submitted to $7^{\text {th }}$ International Conference on Mechanical and Physical Behavior of Materials under Dynamic Loading, Porto, Portugal, September 8-12, 2003

U.S. Department of Energy

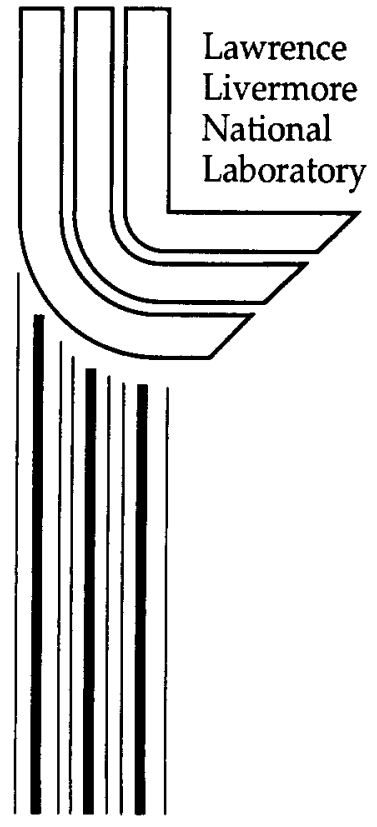

July 27, 2003 


\section{DISCLAIMER}

This document was prepared as an account of work sponsored by an agency of the United States Government. Neither the United States Government nor the University of California nor any of their employees, makes any warranty, express or implied, or assumes any legal liability or responsibility for the accuracy, completeness, or usefulness of any information, apparatus, product, or process disclosed, or represents that its use would not infringe privately owned rights. Reference herein to any specific commercial product, process, or service by trade name, trademark, manufacturer, or otherwise, does not necessarily constitute or imply its endorsement, recommendation, or favoring by the United States Government or the University of California. The views and opinions of authors expressed herein do not necessarily state or reflect those of the United States Government or the University of California, and shall not be used for advertising or product endorsement purposes.

This is a preprint of a paper intended for publication in a journal or proceedings. Since changes may be made before publication, this preprint is made available with the understanding that it will not be cited or reproduced without the permission of the author.

This work was performed under the auspices of the United States Department of Energy by the University of California, Lawrence Livermore National Laboratory under contract No. W-7405-Eng-48.

This report has been reproduced directly from the best available copy.

Available electronically at http://www.doc.gov/bridge

Available for a processing fee to U.S. Department of Energy

And its contractors in paper from

U.S. Department of Energy

Office of Scientific and Technical Information

P.O. Box 62

Oak Ridge, TN 37831-0062

Telephone: (865) 576-8401

Facsimile: (865) 576-5728

E-mail: reports@adonis.osti.gov

Available for the sale to the public from

U.S. Department of Commerce

National Technical Information Service

5285 Port Royal Road

Springfield, VA 22161

Telephone: (800) 553-6847

Facsimile: (703) 605-6900

E-mail: orders@ntis.fedworld.gov

Online ordering: http://www.ntis.gov/ordering.htm

\section{OR}

Lawrence Livermore National Laboratory

Technical Information Department's Digital Library

http://www.llnl.gov/tid/Library.html 


\section{EXPERIMENTAL RESULTS}

Penetration experiments into high strength concrete and an in-situ granite formation located in the Climax Ridge region of the Nevada Test Site were conducted with the XC-G1 shaped charge. The concrete density was $2.3 \mathrm{~g} / \mathrm{cc}$ with an unconfined compressive strength of $6000 \mathrm{psi}$. The granite gensity was 2.65 $\mathrm{g} / \mathrm{cc}$. The experimental results include the $2 \mathrm{CD}$ standoff hole profiles and penetration versus standoff.

\subsection{Hole Profiles}

The 2 CD standoff target hole profiles in the concrete and granite targets are shown in Figure 2. The tick marks are spaced $2.5 \mathrm{~cm}$ apart. Note that the conical surface spall crater, observed in typical experiments, is not shown and the entrance borehole is extended back to the target surface in the figure. The entrance borehole diameters (measured beyond the surface spall crater) are $5.0 \mathrm{~cm}$ for the concrete and $3.5 \mathrm{~cm}$ for the granite. The $2 \mathrm{CD}$ standoff depth of penetration in concrete is $90 \mathrm{~cm}$ and $75 \mathrm{~cm}$ into the granite.

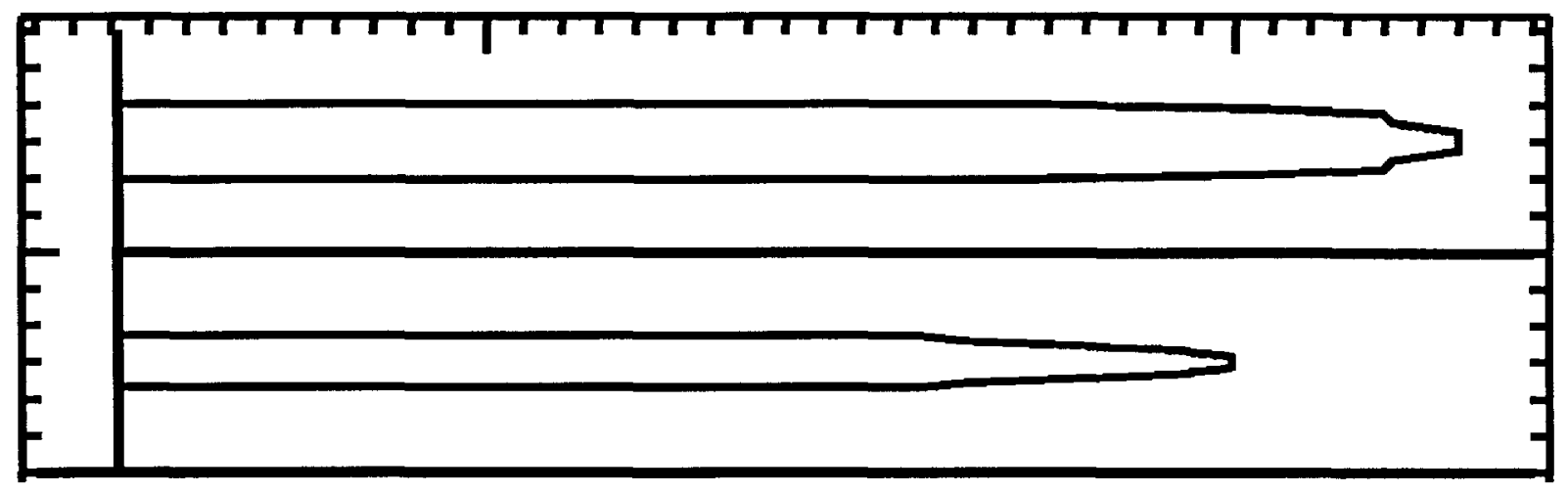

Figure 2. Comparison of concrete (upper) and granite (lower) hole profiles from the $2 \mathrm{CD}$ standoff jet penetration.

\subsection{Penetration versus Standoff}

The results of the penetration versus standoff experiments into the concrete and granite targets are shown in Figure 3. The plot axis dimensions are charge diameters $(12.7 \mathrm{~cm})$. The three initial granite experiments were conducted at $2,3, \& 4$ CD standoff (triangles, solid line). The granite penetration at $2 \mathrm{CD}$ standoff is about $1 \mathrm{CD}$ less than the penetration depth into concrete. The $3 \&$ $4 \mathrm{CD}$ standoff experiments were even less than the $2 \mathrm{CD}$ standoff penetration depth which is quite unusual at such a short standoff. We noted large target fractures in $3 \& 4 \mathrm{CD}$ standoff experiments and suspect that edge effects contributed to the degradation in penetration. The $4 \mathrm{CD}$ standoff experiment was repeated into a larger and more intact granite out cropping. This penetration depth was about $1 \mathrm{CD}$ less than the penetration measured in concrete. It is also more consistent with the $2 \mathrm{CD}$ standoff experimental results into the granite.

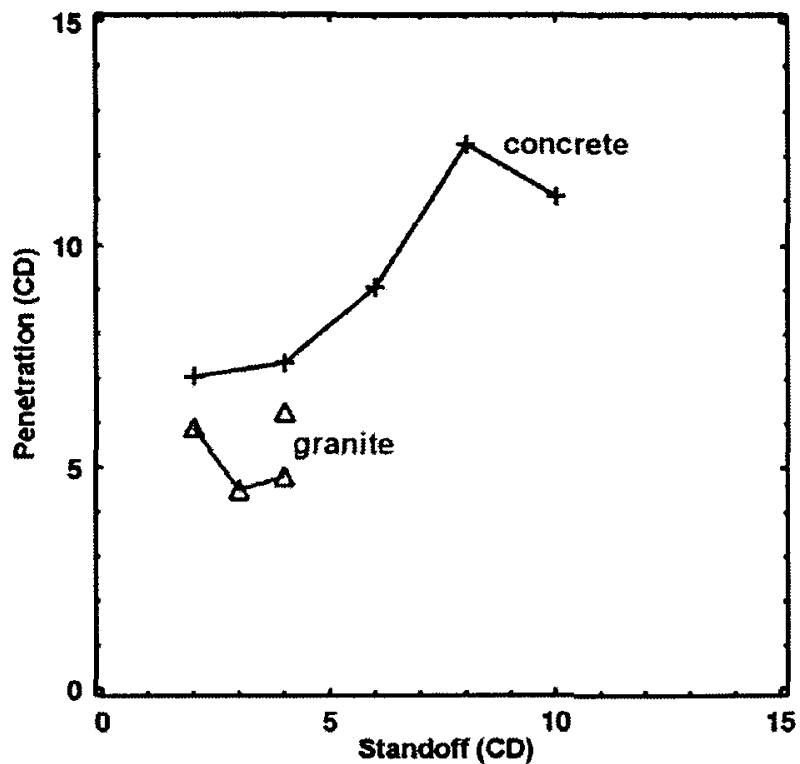

Figure 3. Comparison of concrete and granite penetration versus standoff (in charge diameters). 


\title{
Experiments and Simulations of Penetration into Granite by an Aluminum Shaped Charge
}

\author{
M.J. Murphy, G. Randers-Pehrson, RM. Kuklo, T.A. Rambur, L.L. Switzer, M.A. Summers \\ Lawrence Livermore National Laboratory \\ PO Box 808, Livermore, CA 94550 USA
}

\begin{abstract}
This paper describes experimental results and numerical simulations of jet penetration into granite from an aluminum lined shaped charge. Several penetration versus standoff experiments were conducted into an in-situ granite formation located in the Climax Ridge region of the Nevada Test Site. Simulations of the jet penetration were modeled with a two dimensional arbitrary lagrange eulerian hydrocode. The effects of variations in the granite flow stress, porosity, and EOS have been evaluated. The work described in this paper is a continuation of our studies on jet penetration and modeling into high strength concrete [1].
\end{abstract}

\section{INTRODUCTION}

In our previous paper we reviewed and evaluated material models for simulation of shaped charge jet penetration in concrete [1]. Simulations were compared to experimental results for a shaped charge fired into high strength concrete. In our present effort we simulate the penetration of a new shaped charge design (XC-G1) test fired into high strength concrete and in-situ weathered granite. The simulations have focused on matching the target hole profile at 2 charge diameter (CD) standoff in both materials through variations in the pressure dependent flow stress and the porosity used in the porous equation of state.

\section{SHAPED CHARGE DESCRIPTION}

The XC-G1 charge shown in Figure 1 is the new baseline shaped charge used for our jet penetration experiments into granite. This charge has a diameter of $12.7 \mathrm{~cm}$ with an $1 / \mathrm{d}$ of about 1 . It is has a thin aluminum case, plastic rear cover, and is loaded with LX-14. Detasheet is used to burn around the foam wave shaper for peripheral initiation. It has a variable angle, variable thickness aluminum liner that was optimized to bore a cylindrical hole in the target by delivering constant energy to the target during the penetration. Except for the change in liner geometry, this "X-Charge" is similar to shaped charges used in previous LLNL concrete target penetration studies [1-4]. The short $\mathrm{L} / \mathrm{D}$ class of charge has also been studied by Kennedy [5] and Mattsson [6].

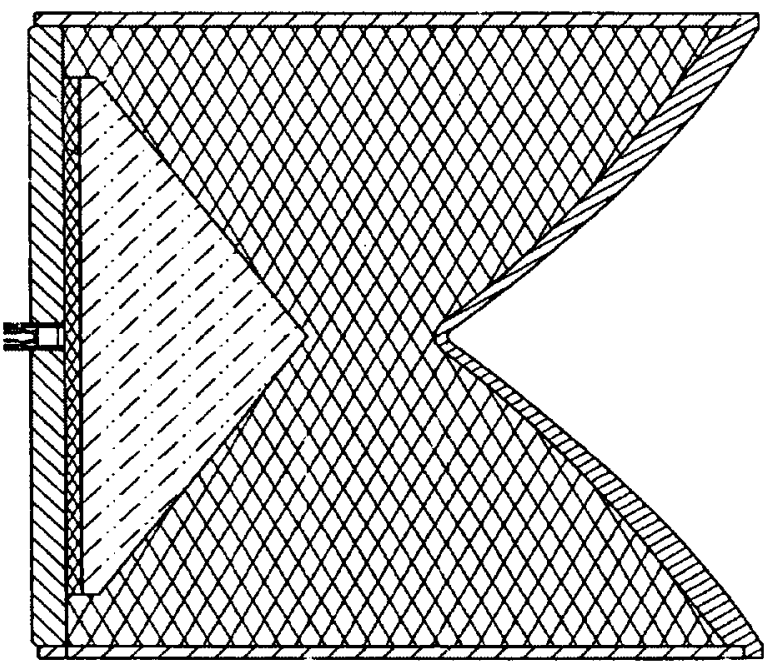

Figure 1. Variable angle/thickness XC-G1 charge 


\subsection{CONCRETE AND GRANITE MATERIAL MODELS}

The simulations have focused on understanding the effect of varying two key aspects of the concrete and granite material models; the porosity used in the porous equation of state and the pressure dependent flow stress. The simulations of hole profile are compared to the experimental hole profiles at $2 \mathrm{CD}$ standoff.

\subsection{Equation of State}

We used a porous equation of state (EOS) to describe the pressure, volume, energy relationship of the concrete and granite. The pressure $(P)$ given in Eq.1 is a function of the porosity $(P O R)$ and the solid pressure $\left(P_{s}\right)$. In Eq. 2, $P_{s}$ is given as a function of the $A$ and $B$ input parameters, the compression (MU) and internal energy $(E)$. The compression $(M U)$, shown in Eq. 3, is a function of the solid density $\left(D E N_{s}\right)$ and reference density $(R E F D)$ which are initially equal. Finally, the solid density $\left(D E N_{s}\right)$ is defined as a function of the current density $(D E N)$ and porosity $(P O R)$ of the material.

$$
\begin{aligned}
& P=(1.0-P O R) * P_{s} \text { (1) } \quad P_{s}=A_{1} * M U+A_{2} * M U^{2}+A_{3} * M U^{3}+\left(B_{0}+B_{1} * M U\right) * E \\
& M U=\left(D E N_{s} / R E F D\right)-1 \\
& \text { (3) } \quad D E N_{s}=D E N /(1.0-P O R)
\end{aligned}
$$

The baseline input values of the parameters for concrete and granite are given in Table 1. Pressurevolume plots for the baseline $12 \%$ porous concrete and a non-porous concrete are shown in blue in Figure 4. Pressure-volume plots for the baseline $0.19 \%$ porous granite and $2 \%$ porous granite are shown in red.

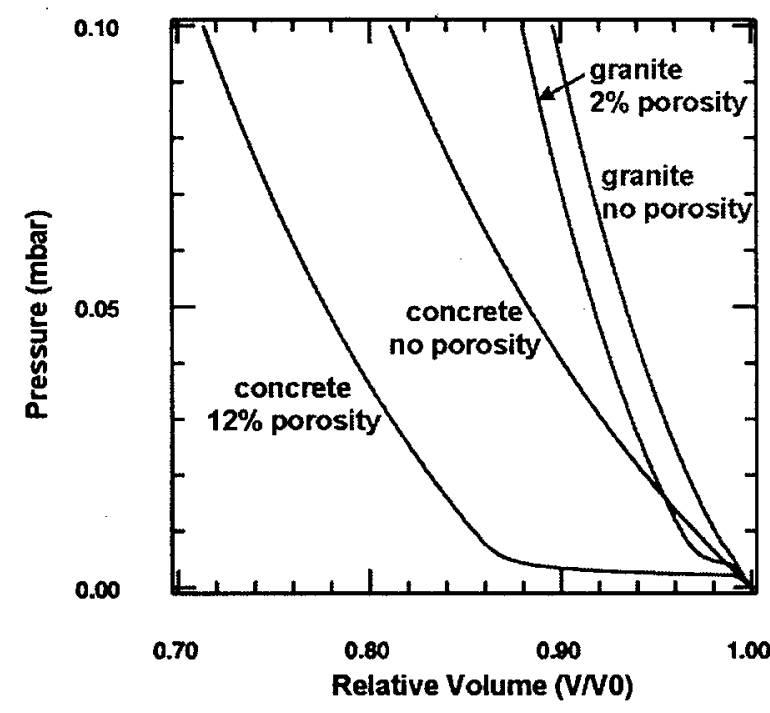

Figure 4. Pressure as a function of relative volume

\begin{tabular}{|c|c|c|}
\hline & Concrete & Granite \\
\hline REFD $(g / c c)$ & 2.623 & 2.657 \\
\hline DEN (g/cc) & 2.308 & 2.652 \\
\hline POR (\%) & $12 \%$ & $0.19 \%$ \\
\hline A1 & 0.3122 & 0.504 \\
\hline A2 & 0.4396 & 3.0275 \\
\hline A3 & 0.1693 & 0.188 \\
\hline B0 & 0.1 & 0.50 \\
\hline B1 & 0.1 & 0.0 \\
\hline
\end{tabular}

Table 1. Values of the EOS parameters.

\subsection{Strength Model}

The strength model used in the simulations defines the yield strength as a tabulated function of the pressure. We use 5 data points to describe a simple flow stress - pressure relationship as shown in Figure 5. We start by defining the unconfined compressive strength ( $\mathrm{fc}$ ) at a pressure of fc/3. Projecting back to a tensile pressure of negative $\mathrm{fc} / 30$, we define the flow stress as $\mathrm{fc} / 10$. The zero flow stress value is defined at a pressure of negative $\mathrm{fc} / 40$. We use a strength/pressure slope of unity to project forward from the unconfined compressive strength to the limiting value of the flow stress. We keep the ratio of the shear modulus to yield strength constant. The values of the baseline input parameters for the concrete and granite are given in Table 2. 


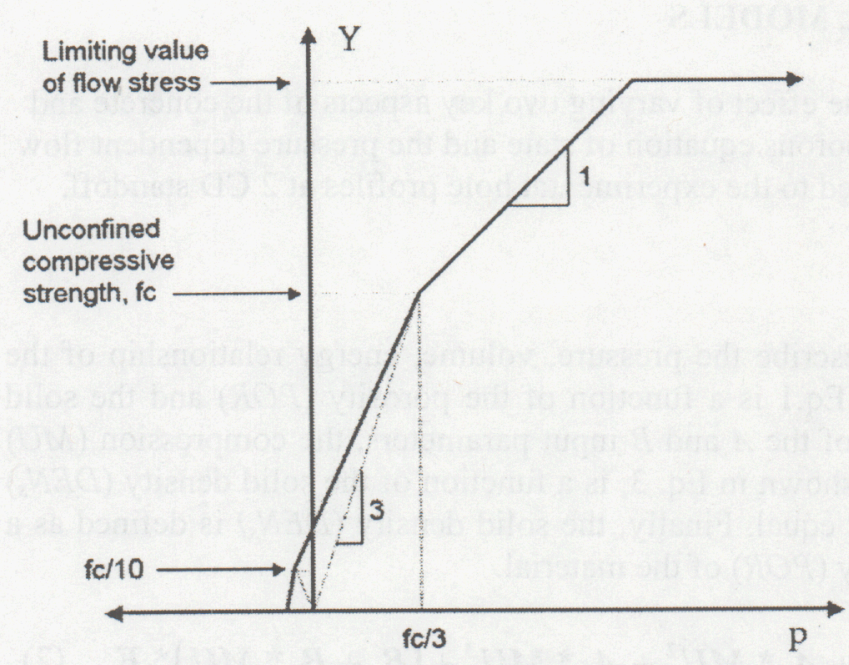

Figure 5. Flow stress as a function of pressure.

\begin{tabular}{|c|c|c|}
\hline $\begin{array}{c}\text { Shear Mod } \\
\text { (mbar) }\end{array}$ & Concrete & Granite \\
\hline $\begin{array}{c}\text { Pressure } \\
\text { (mbar) }\end{array}$ & $\begin{array}{c}\text { Yield } \\
\text { (mbar) }\end{array}$ & $\begin{array}{c}\text { Yield } \\
\text { (mbar) }\end{array}$ \\
\hline-0.0000065 & 0.0 & 0.0 \\
\hline-0.000008667 & 0.000026 & 0.000026 \\
\hline 0.00008667 & 0.00026 & 0.00026 \\
\hline 0.01583 & 0.016 & 0.016 \\
\hline 0.0160 & 0.016 & 0.016 \\
\hline
\end{tabular}

Table 2. Values of the strength parameters.

\subsection{CONCRETE MODELING STUDIES}

The concrete modeling studies consisted of simulating the jet penetration of the XC-G1 charge with three different EOS's; baseline, no-porosity with the porous model, and non-porous with a Gruneisen model. The strength model was held constant. A comparison of the experimental hole profile with a simulation using the baseline EOS with baseline strength model is shown in the top two frames of Figure 6. Since the granite material is basically non porous, we decided to first evaluate the effect of no porosity with concrete simulations of the hole profile with non-porous models. Two of the concrete EOS's are shown in Figure 4. The lower frame of Figure 6 shows the simulated hole profile using a simple US-UP (c $=0.225$, $\mathrm{s} 1=1.33$ ) hugoniot EOS with data from Gregson [7]. Neither the non-porous EOS nor the Hugoniot EOS provide as well of a match to the experimental results as the baseline simulation. The purpose of simulations presented in the lower 2 frames of the figure was to evaluate EOS porosity effects in concrete as we prepared to evaluate the effects of EOS porosity in a virtually non-porous granite material.

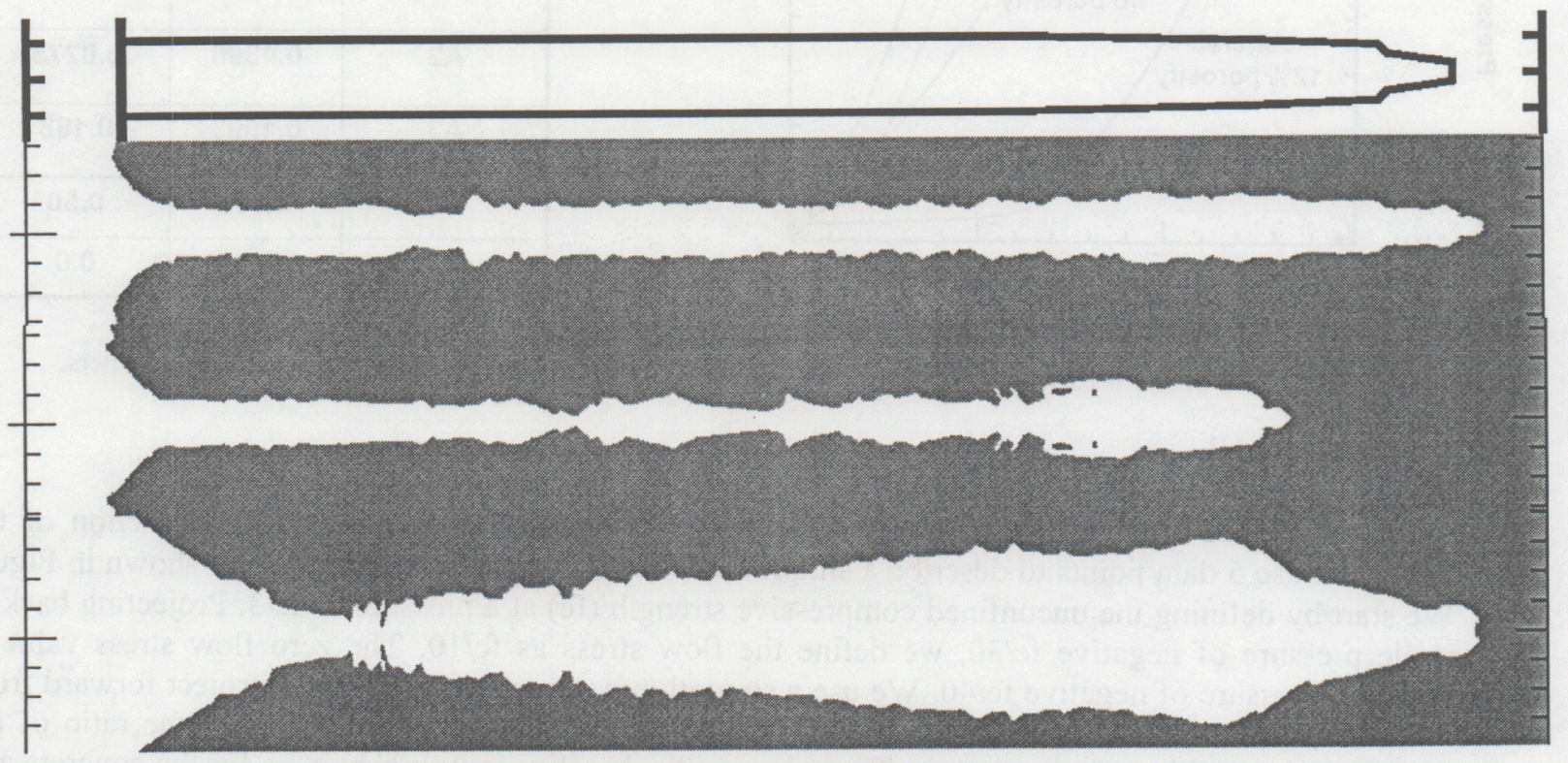

Figure 6. $2 \mathrm{CD}$ standoff experimental concrete hole profile (top) compared to simulations using different concrete EOS's. 


\subsection{GRANITE MODELING STUDIES}

The granite modeling studies examined the granite strength effects and the granite porsosity effects. The baseline granite model parameters given in Tables $1 \& 2$ are from Clark [8] based on data from Hoek [9].

\subsection{Granite Strength Model Effects}

The $2 \mathrm{CD}$ standoff experimental hole profile in granite is shown in the top frame of Figure 7. The second frame from the top shows the simulated hole profile using the baseline granite material properties. Comparing these two frames we see that the hole diameter in the simulation is too large while the depth of penetration is not large enough. In our previous work with concrete [1] we saw that the target hole diameter is very sensitive to the target yield strength. The lower four frames of the figure show the same effect in granite as the strength value in the strength versus pressure table is increased by a factor of 1.1, $1.5,2.0$, and 4.0 . We see that a $10 \%$ increase in strength provides a hole diameter that is more consistent with the experimental results. Unfortunately, the calculated depth of penetration is more than one CD less than the experiment.

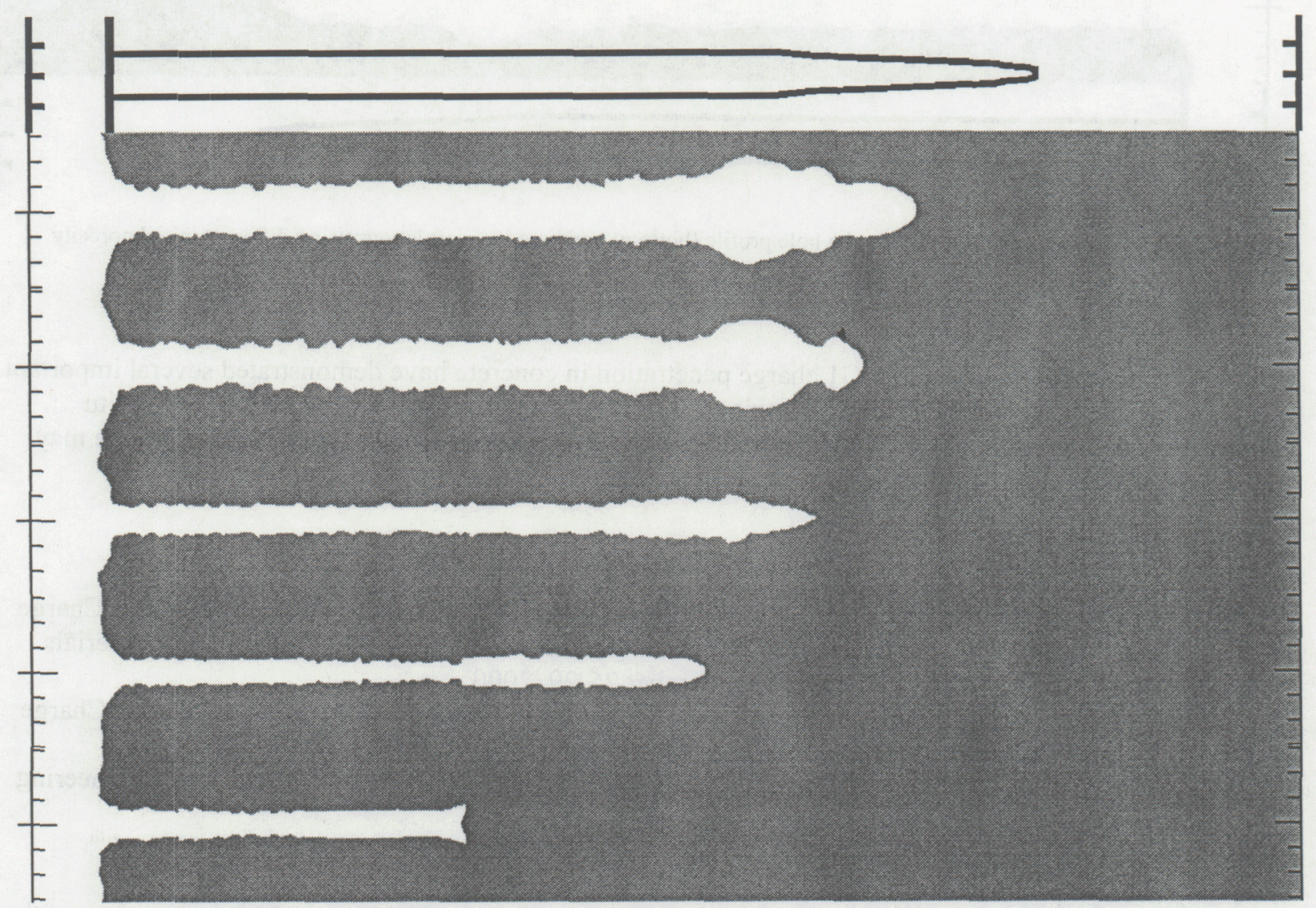

Figure 7.2 CD standoff experimental granite hole profile (top) compared to simulations using different values of yield strength.

\subsection{Granite Porosity Model Effects}

The in-situ granite that the XC-G1 shaped charge was fired into is part of a geologic out-cropping located at the Climax Ridge at the Nevada Test Site. The experiments were fired into weathered, but intact, surface material. As such, we wanted to consider the possibility of minor porosity in the granite and in our simulations. We achieved this in our calculations by decreasing the initial density (DEN) of the granite by $1 \%$ and $2 \%$. The results of these simulations are shown in Figure 8 . The top frame is the 2 CD standoff 
simulation result with the baseline granite material model parameters presented in Tables $1 \& 2$. The next two frames are the simulation results with $1 \%$ initial porosity and $2 \%$ initial porosity. The lower frame is the $2 \mathrm{CD}$ standoff experimental hole profile. We see that the $2 \%$ porosity simulation with the baseline strength model (same as high strength concrete) provides a good match to the experiment.

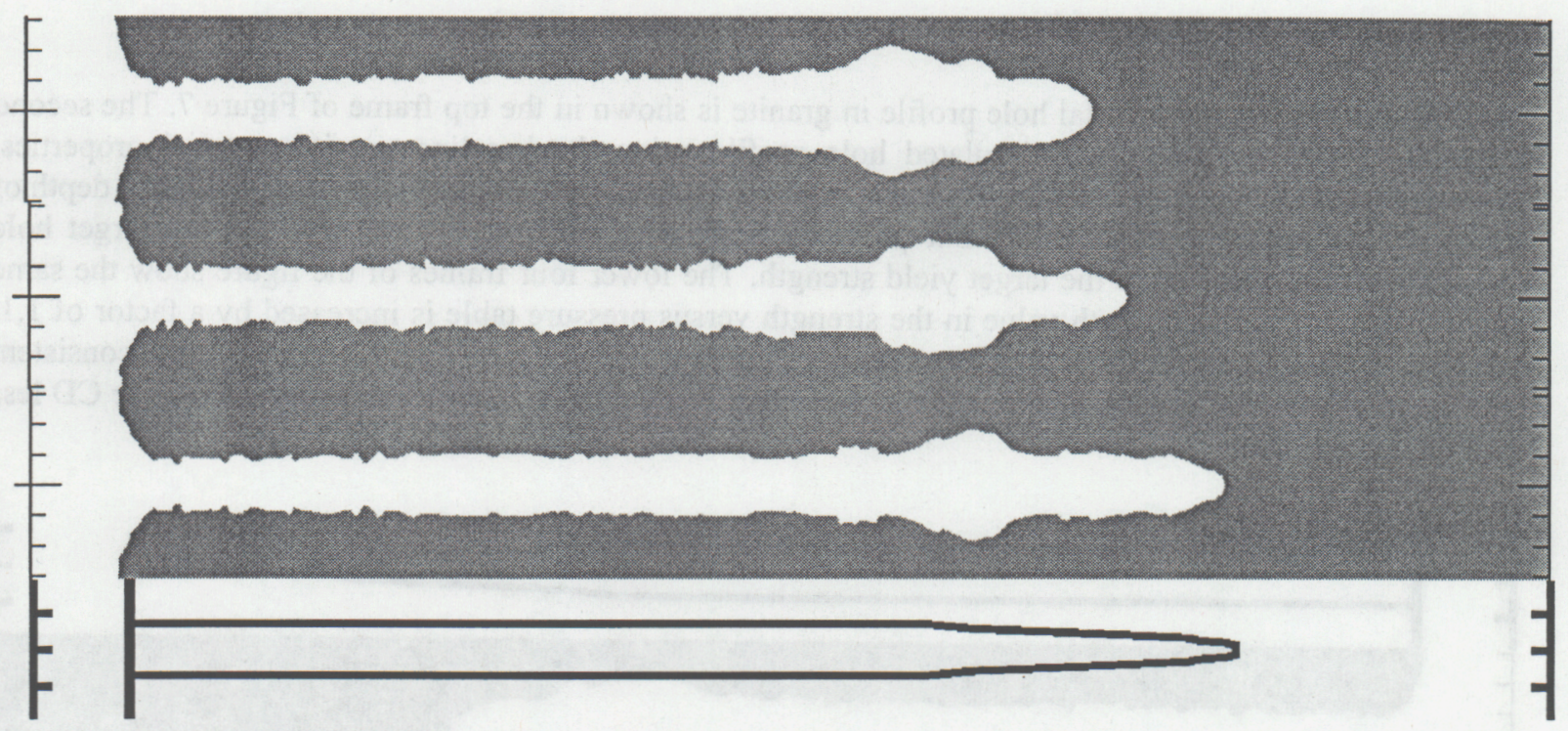

Figure 8. $2 \mathrm{CD}$ standoff experimental granite hole profile (bottom) compared to simulations using different initial porosity.

\section{SUMMARY}

These initial simulation of the XC-G1 charge penetration in concrete have demonstrated several important findings: it is important to model the geologic materials with a porous model, the porosity of in-situ weathered, intact granite may be a large as $2 \%$, and the strength of in-situ weathered, intact granite may be very similar to the strength of high strength concrete.

\section{REFERENCES}

[1] M.J. Murphy, et al, "Numerical Simulation of Damage and Fracture in Concrete from Shaped Charge Jets", DYMAT 2000, $6^{\text {th }}$ International Conference on Mechanical and Physical Behaviour of Materials Under Dynamic Loading, Krakow, Poland, September 25-29, 2000

[2] Murphy M.J. and Henderson J.M., "Computer Simulation of Concrete Penetration by Shaped Charge Jets", 7th International Symposium on Ballistics, The Hague, Netherlands, April 1983.

[3] Murphy M.J., "Shaped Charge Penetration in Concrete: A Unified Approach", Doctor of Engineering Dissertation, UCRL-53393, January 1983.

[4] Murphy M.J. and Kuklo R.M., "Fundamentals of Shaped Charge Penetration in Concrete", $18^{\text {th }}$ International Symposium On Ballistics, San Antonio, TX, November 1999.

[5] Kennedy D.R., "History of the Shaped Charge Effect - The First 100 Years", $100^{\text {th }}$ Anniversary of the Discovery of the Shaped Charge Effect", MBB Schrobenhausen, Germany, 20-22 September, 1983.

[6] Mattsson K., et. al., "Development of the K-Charge, A Short L/D Shaped Charge", $18^{\text {th }}$ International Symposium On Ballistics, San Antonio, TX, November 1999.

[7] V.G. Gregson Jr., A Shock wave study of Fondu-Fyre WA-1 and a concrete", General Motors Materials and Structures Laboratory, Report MSL-70-30, 1971.

[8] D. Clark, personal communication, September 2002.

[9] Hoek, Evert And Brown, Edwin T., Underground Excavations In Rock, London : Institution Of Mining And Metallurgy 1980 